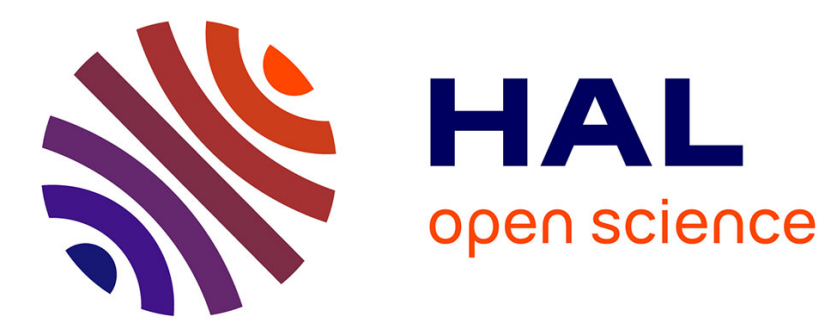

\title{
Components interactions controlling starch-kaolinite composite films properties
}

\author{
Jean Aimé Mbey, Fabien Thomas
}

\section{To cite this version:}

Jean Aimé Mbey, Fabien Thomas. Components interactions controlling starch-kaolinite composite films properties. Carbohydrate Polymers, 2014, 10.1016/j.carbpol.2014.10.053. 10.1016/j.carbpol.2014.10.053 . hal-01079322

\section{HAL Id: hal-01079322 \\ https://hal.science/hal-01079322}

Submitted on 31 Oct 2014

HAL is a multi-disciplinary open access archive for the deposit and dissemination of scientific research documents, whether they are published or not. The documents may come from teaching and research institutions in France or abroad, or from public or private research centers.
L'archive ouverte pluridisciplinaire HAL, est destinée au dépôt et à la diffusion de documents scientifiques de niveau recherche, publiés ou non, émanant des établissements d'enseignement et de recherche français ou étrangers, des laboratoires publics ou privés. 


\section{Accepted Manuscript}

Title: COMPONENTS INTERACTIONS CONTROLLING STARCH-KAOLINITE COMPOSITE FILMS PROPERTIES

Author: J.A. Mbey F. Thomas

PII:

S0144-8617(14)01065-0

DOI: http://dx.doi.org/doi:10.1016/j.carbpol.2014.10.053

Reference:

CARP 9406

To appear in:

Received date:

Revised date: $16-10-2014$

Accepted date:

Please cite this article as: MBEY, J. A., and THOMAS, F.,COMPONENTS INTERACTIONS CONTROLLING STARCH-KAOLINITE COMPOSITE FILMS PROPERTIES, Carbohydrate Polymers (2014), http://dx.doi.org/10.1016/j.carbpol.2014.10.053

This is a PDF file of an unedited manuscript that has been accepted for publication. As a service to our customers we are providing this early version of the manuscript. The manuscript will undergo copyediting, typesetting, and review of the resulting proof before it is published in its final form. Please note that during the production process errors may be discovered which could affect the content, and all legal disclaimers that apply to the journal pertain. 
4

5

6

11

$15 *$ Corresponding author: e-mail: mbey25@yahoo.fr or jean-aime.mbey@univ-lorraine.fr 16 Tel: +23799238925 COMPOSITE FILMS PROPERTIES

${ }^{a}$ Université de Lorraine, Laboratoire Interdisciplinaire des Environnements Continentaux, UMR 7360 , 15 Avenue du Charmois, B.P. 40. F-54501, Vandoeuvre-lès-Nancy Cedex

${ }^{\mathrm{b}}$ CNRS, Laboratoire Interdisciplinaire des Environnements Continentaux, UMR 7360, 15 Avenue du Charmois, B.P. 40. F-54501, Vandoeuvre-lès-Nancy Cedex

${ }^{c}$ The University of Yaoundé I, Department of Inorganic Chemistry, Laboratory of Applied Inorganic Chemistry, P.O. Box 812 Yaoundé

MBEY Jean Aimé: mbey25@yahoo.fr; jean-aime.mbey@univ-lorraine.fr

THOMAS Fabien: fabien.thomas@univ-lorraine.fr 4 


\section{Abstract}

In order to relate the primary filler-matrix interactions to the macroscopic properties of starchkaolinite composite material, these interactions are monitored through homo- or heterocoagulation experiments involving both components. Turbidity measurement and Infrared spectra confirm the extreme weakness of the interactions. The addition of calcium cations shows that these weak interactions between starch and kaolinite are due to the combination of the electrostatic repulsion and hydrogen bonds formation between this two negatively charge components. Some possible relationships between the starch-kaolinite interactions and starchkaolinite composite films properties are proposed.

Keys words: Kaolinite; Starch; Composite; Coagulation; Interface.

\section{1 : Introduction}

Starch and kaolinite are readily available, low cost materials that have already found uses in several domain such as composite materials (Kaewtatip and Tanrattanakul, 2012 ; Mbey et al., 2012a; Chen and Evan, 2005; de Carvalho et al., 2001; Whilem et al., 2003), paper coating (Husband, 1998), flotation of iron ore (Ma, 2011; Ma, 2010; Ma et Bruckard, 2010; Liu et al., 2000; Weissenborn et al., 1995), water treatment (Shogren, 2009 ; Bolto and Gregory, 2007 ; Krentz zt al._2006 ; Järnström et al. 1995a ; Järnström et al. 1995b). In some cases, starch undergoes some modifications prior to its use in a particular domain. Cationic starch derivatives for instance are usually of interest in flocculation of solid matter from water (Bratskaya et al., 2005 ; Chen et al., 2007 ; Wei et al., 2008 ).

In the domain of polymer-clay composite, the filler-polymer matrix interactions are one major key for properties change understanding. Those interactions are influenced by the filler-matrix interface and/or interphase, the filler particles orientation, the filler dosages, the filler particles anisotropy, the surface properties of the filler or the filler dispersion (Fu et al., 2008; Tran et al., 2006; Wu et al., 2002; Pukansky, 1990). In those materials, the interactions between the organic matrix and the inorganic filler determine structural and aging properties. Strong interactions guarantee rigidity and resistance to abrasion, weak interactions are required for flexibility. (Lopez et al., 2014; Müller et al., 2014; Jandas et al., 2013; Reddy et al., 2013).

Hence, the explanation of properties changes in composites are discussed on the basis of the filler-polymer matrix interactions. Lopez at al. (2014) associated the ductility conservation in starch-talc composite to low interactions between starch and talc particles. Müller et al. (2014), used wood particles to improve thermoplastic starch properties. They show that the wood particles having large aspect ratio improve the stiffness and the strength of the 
composite. Also, strong interfacial adhesion between the wood particles and the starch matrix decreases the starch chains mobility and reduces the water uptake of the composite. In our previous works (Mbey et al., 2012 and 2014), unmodified or DMSO-intercalated kaolinite are used as filler in thermoplastic starch based films. The filler particle orientation and the low kaolinite dosage, together with weak kaolinite-starch interactions better account for the plasticity increase within the film. Better dispersion of the DMSO-intercalated kaolinite shows larger properties changes compared to unmodified kaolinite filled films. It is then believed that analysing the primary interactions between the components of the composite may be useful to understand the composite properties. Hence, in the case of kaolinitethermoplastic starch composite, the study of starch-kaolinite interactions is of interest.

To date, general studies on the kaolinite-starch interactions are rare (Ma, 2011; Ma, 2010; Ma et Bruckard, 2010), especially in the field of starch-clay composites. In fact, those interactions are described as very weak, since the essentially non ionic hydroxylic functions available on both starch and clay interface give rise to physical sorption through hydrogen bonds.

For this study, we will attempt to correlate the starch-kaolinite interactions to the properties of starch-kaolinite composite films.

This study aims at monitoring the adsorption of cassava starch onto kaolinite as a way to understand the starch-kaolinite films properties. The dispersion or the coagulation of the kaolinite phase during composite processing will largely depend on the kaolinite-starch interactions. Absence of interactions could favour phase separation between the two components, whereas strong interactions may induce the coagulation of the clay within the polymer matrix or increase the polymers chain rigidity within the composite. On this basis, it is then obvious that weak to medium interactions are preferred for viscoelastic composite films making. To access the starch-kaolinite interactions, the sedimentation/flocculation test of dilute kaolinite suspension in presence of natural cassava starch is used.

\section{2 : Experimental section}

\section{2-1: The Kaolinite material}

The raw kaolinite was collected from a deposit situated in Mayouom (western Cameroon) (Njoya et al., 2006). The sample used in the present study was taken at $3 \mathrm{~m}$ depth. The fraction $<40 \mu \mathrm{m}$, labelled $\mathrm{K} 3$, was collected by means of wet sieving. Using inductive coupled plasma by atomic emission spectrometry (ICP-AES) to analyze the major elemental composition of the sample, an approximation of the structural formula of the kaolinite phase 
was found to be $\left(\begin{array}{llll}\mathrm{Al}_{1.94} & \mathrm{Fe}_{0.06}\end{array}\right)\left(\mathrm{Si}_{1.98} \mathrm{Fe}_{0.02}\right) \mathrm{O}_{5}(\mathrm{OH})_{4}\left(\mathrm{Mg}_{0.02} \mathrm{Ca}_{0.002}\right)$. The mineralogical composition of the sample is as follows: Kaolinite $83.3 \%$; Illite $10.4 \%$; Titanium oxide 3.4 $\%$. The fine clay fraction was collected through sedimentation after Stokes' law. The particle size distribution of the collected fraction was analysed using a Sympatec laser diffraction granulometer equipped with the HELOS optical system and the WINDOX software for data acquisition. The average particle size (D50) was found to be $4.5 \mu \mathrm{m}$ and more than $80 \%$ of the material has size less than $7.5 \mu \mathrm{m}$. The BET specific surface area, determined by nitrogen adsorption using an automatic homemade apparatus, was $(25.9 \pm 0.1) \mathrm{m}^{2} / \mathrm{g}$. The cation exchange capacity (CEC) was measured using hexaminecobalt(III) chloride $\left[\mathrm{Co}\left(\mathrm{NH}_{3}\right)_{6} \mathrm{Cl}_{3}\right]$. The amount of hexaminecobalt(III) sorbed by the solid phase was determined by colorimetric measurement at $472 \mathrm{~nm}$ using UV-vis spectroscopy and the CEC was found to be 6.0 meq/100g.

\section{2-2: The starch material}

The cassava starch was obtained by aqueous extraction from cassava tubers produced in Mambando (Centre Cameroon). Starch material was manually ground and sieved at $100 \mu \mathrm{m}$. The sieved starch was stored in high density polyethylene container at ambient temperature. The moisture content, determined by drying to constant weight at $105^{\circ} \mathrm{C}$, is $14 \%$. Content in mineral ashes, determined by ignition at $550{ }^{\circ} \mathrm{C}$ in a muffle furnace, is $0.3 \%$. Elemental analysis using the CHNS analyser Carlo Erba 1108, indicated respective contents of carbon (39.1\%), hydrogen $(7.5 \%)$ and nitrogen $(0.05 \%)$. The $\mathrm{H} / \mathrm{C}$ ratio, 5.2 is common for polysaccharides. The very low nitrogen content, and the absence of the characteristic amine band in the FTIR spectrum (not presented) indicate negligible content of proteins.

\section{2-3: Experimental procedures}

The kaolinite suspension was prepared by dilution of the aqueous extract of fine clay fraction to a solid concentration of $0.5 \mathrm{mg} / \mathrm{mL}$ of turbidity $235 \mathrm{NTU}$ (HACH $2100 \mathrm{~N}$ turbidimeter).

The starch solution was prepared by dissolving $100 \mathrm{mg}$ of starch in $5 \mathrm{~mL}$ of analytical grade DMSO (Sigma Aldrich $99.99 \%$ ) under heating at $60{ }^{\circ} \mathrm{C}$ during $5 \mathrm{~min}$. The mixture was then diluted with deionised water $\left(18.2 \mathrm{M} \Omega \mathrm{cm}^{-1}\right)$ to obtain $100 \mathrm{~mL}$ of solution (starch concentration $1 \mathrm{mg} / \mathrm{mL}$ ). The dissolution with DMSO prevents alteration of the chemical functions and degradation of the carbohydrate chains (Han et Lim, 2004). The working pH was selected after analysing its effect on the sedimentation of the kaolinite suspension. Typically $30 \mathrm{~mL}$ of the initial suspension having $235 \mathrm{NTU}$ turbidity was taken and used at the 
117 spontaneous $\mathrm{pH}$ reached by the suspension (6.02) or after adjusting the $\mathrm{pH}$ value by adding 118 aliquot of $0.1 \mathrm{M}$ solution of either $\mathrm{NaOH}$ or $\mathrm{HNO}_{3}$. The samples are left for sedimentation 119 during 40 min after which $15 \mathrm{~mL}$ of the suspension supernatant was taken using a 120 micropipette for turbidity measurements. On figure 1, are reported the results obtained. It can 121 be noted that the turbidity is stabilized around 160 NTU. This reduction of turbidity is caused 122 by the settling of large particles that arise from collision between the clay particles subject to 123 Brownian motion. The acid or alkaline value of $\mathrm{pH}$ induced either protonation or deprotonation of edge functions $(=\mathrm{AlO}-\mathrm{H}$ and $=\mathrm{SiO}-\mathrm{H})$. Given that the permanent charge of the clay is negative, hence deprotonation of the edge functions, in alkaline $\mathrm{pH}$, increasing the global negative charge of the suspension which result in an increase electrostatic repulsion that prevent particles collision and hence, stabilized the suspension. Conversely, in acid $\mathrm{pH}$, the edge functions are positively charge inducing then a reduction of the global electrostatic repulsion. This charge reduction favours collision that result in increase particle size that settled under their weight. This explains why, acid $\mathrm{pH}$ favours the sedimentation and alkaline $\mathrm{pH}$ slightly increases suspension stability. Intermediate $\mathrm{pH}$, reached spontaneously by the kaolinite suspension $(\mathrm{pH}=6.2)$, was considered as an optimal starting condition for further coagulation experiments.

134 The proton surface excess of both kaolinite and starch was measured by acid-base titration using a Metrohm Titrando 809 station with two dosing units Dosino 800. The system is automatically driven by the software Tiamo (version 1.2.1 light). The titration of the suspension was carried out under magnetic stirring and argon stream to avoid carbon dioxide dissolution in the suspension. Electrophoretic mobility of the kaolinite and the starch materials was measured in $\mathrm{NaNO}_{3}$ background electrolyte $\left(10^{-3} \mathrm{M}, 10^{-2} \mathrm{M}\right.$ and $\left.10^{-1} \mathrm{M}\right)$ and in the presence of varying amounts of $\mathrm{CaCl}_{2}$ using a Zetaphoremeter $\mathrm{V}$ by $\mathrm{CAD}$ Instrumentation

\section{1 (France).}

142 For the sedimentation tests, $30 \mathrm{~mL}$ of the kaolinite suspensions was magnetically stirred for 5 143 min after addition of known dosages of starch and $\mathrm{CaCl}_{2}$. The samples were then placed in 144 vertical test tubes for sedimentation. After $40 \mathrm{~min}, 15 \mathrm{~mL}$ of the supernatant suspensions was 145 taken for turbidity measurement using $\mathrm{HACH} 2100 \mathrm{~N}$ turbidimeter. The remaining 146 suspensions were freeze-dried and the sediment conditioned in $\mathrm{KBr}$ pellets were analysed by 147 FTIR. The FTIR spectra were recorded using a Bruker IFS 55 interferometer in transmission mode. The sedimentation tests were done in absence or in presence of calcium. A preliminary

150 Uv-vis spectrometer, SHIMADZU UV 2101 PC, was used for kinetic monitoring of the 
151 suspensions sedimentation. The measurements were done at $300 \mathrm{~nm}$.

\section{$152 \quad 3$ : Result and discussion}

\section{3.1: Starch-Kaolinite interactions}

154 The titration curves presented in figure 2, show the $\mathrm{pH}$-dependence of the net proton surface

155 excess. For the starch, the specific amount of acidic groups is around $43 \mu \mathrm{mol} / \mathrm{g}$ (figure $2 \mathrm{~b}$ ).

156 In order to evaluate the spatial distribution of charges on the starch macromolecule, we can

157 assume that the latter is composed of glucose residues of molar mass $180 \mathrm{~g} / \mathrm{mol}$. The obtained

158 charge is then $7.7 \mathrm{mmol}$ of protons per mole of glucose residue, which represents $0.77 \%$ of

159 carboxylated residues (less than $1 \%$ of glucose residues are bind to carboxylate group).

160 The titration curves at different ionic strength are virtually superimposed, which indicates a 161 very low charge.

162 The titration curve of kaolinite quantifies the pH-dependent charges on the edges of the 163 particles $(=\mathrm{A}-\mathrm{O}-$ and $=\mathrm{SiO}-$ ), resulting in a proton surface excess of about $50 \mu \mathrm{mol} / \mathrm{g}$ (figure

164 2a). This surface charge is in accordance with the commonly observed cationic exchange 165 capacity for kaolinites, generally below 10 meq/100g (Eslinger and Pevear, 1988, after Martin and Dacy, 2004). The fact that no common intersection point is observed on the titration curves at different ionic strength indicates the presence of small amount of permanent charge due to isomorphic substitutions in the crystalline structure of the kaolinite. Similar behaviour was observed and modelled for montmorillinites and illites by Delhorme et al. (2010) and could be attributed to the $10 \%$ of illite contained in the sample.

171 From electrophoretic mobility measurements (figure 3), it is shown that the surface charge of

172 both starch and kaolinite is negative in the $\mathrm{pH}$ range of 3 to 10 . The electrophoretic mobility 173 of the starch (figure 3b) shows positive values for $\mathrm{pH}$ below 2.1, which indicates the presence 174 of cationic functions such as ammonium functions in proteins, which were detected in very 175 low amount by elemental analysis (\$2.2). The negative values and $\mathrm{pH}$ dependence of the 176 electrophoretic mobility of starch in the $\mathrm{pH}$ domain $2.5-7$ is probably due to the dissociation 177 of carboxylic groups on the starch macromolecules.

178 The electrophoretic mobility of kaolinite (Figure 3a) shows very little dependence on ionic 179 strength and also on $\mathrm{pH}$ in the domain above $\mathrm{pH}$ 6, which confirms the presence of permanent 180 charges that were detected from the titration curves. In the domain below $\mathrm{pH} 6$, strong $\mathrm{pH}$ 181 dependence of the electrophoretic mobility results from the protonation of the hydroxylic 182 functions on the edges of the clay particles. 
183 Adsorption isotherms are generally used to study the mechanism and strength of interaction 184 between a mineral interface and an organic (macro)molecule. In the present case, such approach is ineffective for at least two reasons. Firstly, the weakness of the interactions does not allow strong amounts of organics to be adsorbed on the solid, as shown in published studies (Liu, 2007; Mpofu et al., 2003; Järnström et al. 1995a). Secondly, in the present study, cassava starch was used in the native form, therefore heterocoagulation experiments are more adapted than adsorption isotherms to study organo-mineral interactions. In figure 4, the turbidity of a kaolinite suspension is independent of the amount of added starch up to $2.5 \%$ (higher amounts would increase the turbidity due to the granular character of starch). Addition of $10^{-5} \mathrm{M} \mathrm{CaCl}_{2}$ results in significant and rapid (40 minutes) sedimentation of the suspension, which confirms that electrostatic repulsions must be overcome to achieve attractive interactions, as also reported by Ma (2010). It is obvious that for dosage between $1 \%$ and 1.5 $\%$, the effect of starch on the sedimentation is maximal. In this study, the calcium ion acts as neutralizer of the kaolinite surface charge, and the screening of the kaolinite charge favours the starch adsorption on the kaolinite surface.

198 The increase in adsorption of starch is evidenced by the decrease in the turbidity (increase sedimentation of the clay) for the same starch concentration in presence of calcium ion (figure 4). The starch adsorption is almost maximal early at $0.33 \%$ dosage of starch. It seems that adsorption of starch at low dosage is possible and this helps the kaolinite sedimentation. However, the adhesion forces are not strong enough and this explains the turbidity fluctuation observed around $1 \%$. Weak interactions take place in the system due to combine effect of hydrogen bonds between the two components and electrostatic repulsion between starch and kaolinite due to their negative surface charge. The hydrogen bonds could be beneficially increase by the reduction of the interaction sphere (that is, a reduction of the volume in which starch and kaolinite interact). Hence, the screening of the kaolinite surface charge by the calcium cations induce then an increase in starch adsorption. The effect of calcium ions on the electrostatic interactions between the clay and the starch is illustrated in figure 3 (c and d). While kaolinite showed to be relatively insensitive to monovalent cations $\left(\mathrm{Na}^{+}\right)$(Figure 3a), its negative electrophoretic mobility dramatically decreases in the presence of $10^{-5} \mathrm{M} \mathrm{Ca}^{2+}$. Comparatively, the mobility of starch is less sensitive to the presence of $\mathrm{Ca}^{2+}$, the complexation of which with carboxyl and eventually dissociated hydroxyls being much weaker than on dissociated surface sites on clay. The charge interaction between kaolinite and starch is hence, reduced and this results in a decrease of the interaction sphere between kaolinite and starch that favours starch adsorption. However, one can easily note that the clay 
surface charge remains negative even in the presence of calcium (figure 3c) as well as the

218 starch surface (figure 3d). The hypothesis to explain the remaining negative charge of the 219 kaolinite in the presence of calcium is that, edge-edge aggregation that leads to loose aggregates takes place within the kaolinite suspension in presence of calcium. These loose aggregates enclose part of the negative charge of kaolinite particles preventing then further screening because of the repulsion between the calcium cation at the external shell of these aggregates. Hence, even if the added calcium cations screened both starch and kaolinite surface, the overall surface of both component remain negative and the electrostatic repulsion between the two components is dominant and favours the stability of the system. FTIR spectra of the raw kaolinite and aggregated sediments are presented in figure 5 . The presence of the band at $1383 \mathrm{~cm}^{-1}$ characterising the $\mathrm{C}-\mathrm{H}$ bending in the pyranose ring (Velraj et al., 2011) is a proof of some starch adsorption onto kaolinite particles. However, as concluded from turbidity measurements, the amount of starch adsorbed is low. The sediments are mostly made of kaolinite as shown by the similarity between the raw kaolinite spectra and that of the freezed-dried sediments. The absence of the band at $1383 \mathrm{~cm}^{-1}$ on the sediment obtained with $2 \%$ starch, is probably due to the loose nature of the aggregate which agree with the previously mentioned weak adhesion force between the two components. It is proposed that natural gravimetric sedimentation is dominant and the contribution of potential coagulation due to both starch and calcium is low.

The kinetic evidence of the influence of starch on the kaolinite sedimentation is presented on figure 6 . The difference between the blank system and systems containing starch, calcium or starch + calcium is obvious. The starting of sedimentation is effective between 10 min and 15 min. The kaolinite sedimentation is increase in the presence of starch. The addition of calcium ameliorate the starch adsorption on the clay which better promotes the kaolinite sedimentation. The increase sedimentation due to starch adsorption is rather low indicating weak adhesion interactions that are clearly related to the surface state of both components which are negatively charged.

\section{3.2: Relating the starch-kaolinite interactions to the starch-kaolinite films properties}

245 In the aim of understanding the properties of composite films, a global view of weak starch246 kaolinite interfacial interactions can explain the good dispersion of the kaolinite within the 247 starch matrix. This view of weak interactions is regarded as a result of the predominance of 248 the electrostatic repulsion between these two negatively charged components and the H-bonds 249 formation due to the existence of hydroxyl groups on the surface of both components. In 250 particular, the existence of electrostatic repulsion is favourable to the clay dispersion. The 
presence of kaolinite between the starch chains with weak kaolinite-starch interactions

252 facilitates the mobility of the starch chains, giving rise to a plasticizing effect of the clay within the starch matrix. These hypotheses correlate well with the decrease of the glass transition temperature reported in a previous work (Mbey et al., 2012). The glycerol molecules, present at the starch-kaolinite interface, may also participate in the interactions within the films network.

Due to the electrostatic repulsion between the two components, the clay particles are better oriented in the starch matrix in the direction that minimizes the repulsion between the two components. Because kaolinite charge is supposed to be more dense on edges surfaces, a preferential basal orientation of the kaolinite particles is expected within the films (figure 7a). Such an orientation may also contribute to an increase in starch chain mobility through an increase of the plasticizer diffusion and prevention of plasticizer escape. The optical micrograph presented in figure $7 \mathrm{~b}$, actually corroborates such an orientation. This orientation also agrees well with barrier properties to water uptake, heat diffusion or UV-light transmission (Mbey et al., 2012). More recently (Mbey et al., 2014), tensile test measurements indicate a decrease in ultimate tensile strength and elastic modulus, in accordance with the decrease of the glass transition temperature previously reported (Mbey et al., 2012). These changes also corroborate the weak starch-kaolinite interactions that allows better gliding of the starch chains and a basal orientation of the clay particles which are consistent with the increase plasticizing effect due to the kaolinite. On figure 8, the experimental evaluation of some critical films properties, namely glass transition temperature and ultimate tensile strength evolution with clay content in the composite films, are given (Mbey et al., 2012 and 2014) to reinforce the propose qualitative correlation of the interfacial interactions with the macroscopic properties.

\section{4 : Conclusion}

276 This study shows possible links between filler-polymer matrix interactions and starch-

277 kaolinite composite films properties. Weak starch-kaolinite interactions, that result from 278 electrostatic repulsion combined to hydrogen bonds formation, evidenced from coagulation tests corroborate the weak interfacial interactions in the composites films. These weak interactions are favourable to preferential basal orientation of clay particles within the film and improve dispersion of the filler. All of which agree with the reported improve plasticization and water uptake, UV light and heat diffusion barrier (Mbey et al., 2012 and 2014). Hence, the dependency of the material properties of the starch-kaolinite film to components interactions is better evidenced. As reported in the literature, this work also 
285 contributes to evidence the fact that composite material properties are dependent on the 286 interactions between the constituents of the composites.

287 
287 Acknowledgements:

288 Celine Caillet is greatly thanked for her help in titrations experiments.

289 


\section{References}

290 Bratskaya S., Schwarz S., Liebert T. et Heinzec T. (2005). Starch derivatives of high degree of functionalization 10. Flocculation of kaolin dispersions. Colloids and Surfaces, A 254, 7580 .

293 Bolto B. and Gregory J. (2007). Organic polyelectrolytes in water treatment. Water research, 294 41, 2301-2324.

295 Chen B. and Evans J. R. G. (2005), Thermoplastic starch-clay nanocomposites and their 296 characteristics, Carbohydrate Polymers, 61, 455- 463.

297 Chen Y., Liu S. and Wang G. (2007). A kinetic investigation of cationic starch adsorption and flocculation in kaolin suspension. Chemical Engineering Journal, 133, 325-333.

De Carvalho, A. J. F., Curvelo, A. A. S. and Agnelli, J. A. M., (2001). A first insight on composites of thermoplastic starch and Kaolin. Carbohydrate Polymers. 45, 189-194.

301 Delhorme M., Labbez C., Caillet C., Thomas F. (2010) : Modelling acid-base properties of 302 2:1 clays. The role of electrostatics. Langmuir 26 (240-9249)

303 Fu S-Y, Feng X-Q, Lauke B. and Mai Y-W., (2008) Effects of particle size, particle/matrix 304 interface adhesion and particle loading on mechanical properties of particulate-polymer composites. Composites: part B, 39, 933-961 Jandas P.J., Mohanty S. and Nayak S.K., (2013). Surface treated banana fiber reinforced poly (lactic acid) nanocomposites for disposable applications. Journal of cleaner production, 52, 392-401.

309 Järnström L., Lason L., Rigdahl M. (1995)a. Flocculation in kaolin suspensions induced by 310 modified starches 1. Cationically modified starch-effets of temperature and ionic strength. 311 Colloids and Surfaces A : Physicochemical and Engineering Aspects. 104, 191-205.

312 Järnström L., Lason L., Rigdahl M.. (1995) b. Flocculation in kaolin suspensions induced by 313 modified starches 2. Oxidized and hydrophobically modified oxidized starch in comparison 314 with poly(vinyl alcohol) and carboxymethylcellulose. Colloids and Surfaces, A104, 207-216. 315 Han J-A and Lim S-T, (2004). Structural changes of corn starches by heating and stirring in 316 DMSO measured by SEC-MALLS-RI system. Carbohydrate Polymers, 55, 265-272.

317 Kaewtatip K. and Tanrattanakul V., (2012). Structure and properties of pregelatinized cassava 318 starch/kaolin composites, Materials and Design, 37, 423-428.

319 Krentz D.O., Lohmann C, Schwarz S., Bratskaya S., Liebert T., Laube J., Heinze T, Kulicke 320 W-M. (2006). Properties and Flocculation Efficiency of Highly Cationized Starch 321 Derivatives. Starch/Stärke. 58, 161-169.

322 Liu P., (2007). Polymer modified clay minerals: A review. Applied Clay Science, 38, 64-76. 
323 López, O.V., Castillo, L.A., García, M.A., Villar, M.A., Barbosa, S.E., (2014). Food

324 packaging bags based on thermoplastic corn starch reinforced with talc nanoparticles, Food 325 Hydrocolloids, doi: 10.1016/j.foodhyd.2014.04.021.

326 Ma M. (2011, May 30). Starch-kaolinite Interactions. SciTopics. Retrieved January 27, 2012, 327 from http://www.scitopics.com/Starch_kaolinite_Interactions.html

328 Ma X. (2010). Role of hydrolyzable metal cations in starch-kaolinite interactions. 329 International Journal of Mineral Processing, 97, 100-103.

330 Ma X. and Bruckard W. J. (2010). The effect of pH and ionic strength on starch-kaolinite 331 interactions. International Journal of Mineral Processing, 94, 111-114.

332 Martin P. and Dacy J., 2004. Effective Qv by NMR core tests. SPWLA 45th Annual Logging 333 Symposium, June 6-9, 2004.

334 Mbey J. A., Hoppe S. and Thomas F. (2012). Cassava-starch kaolinite composite film. Effect 335 of clay content and clay modification on film properties. Carbohydrate polymers, 88, 213336222.

337 Mbey J. A., Hoppe S. and Thomas F. (2014). Cassava-starch kaolinite composite film. 338 Thermal and mechanical properties related to filler-matrix interactions. In Press, Polymer 339 Composites, DOI 10.1002/pc.22928.

340 Mpofu P., Addai-Mensah J., Ralston J. (2003). Investigation of the effect of polymer 341 structure type on flocculation, rheology and dewatering behaviour of kaolinite dispersions.

342 International Journal of Mineral Processing, 71, 247- 268.

343 Müller P., Renner K., Moczo J., Fekete E. and Pukanszky B., (2014). Thermoplastic 344 starch/wood composites: Interfacial interactions and functional properties. Carbohydrate 345 Polymers, 102, 821-829.

346 Njoya A., Nkoumbou C., Grosbois C., Njopwouo D., Njoya D., Courtin-Nomade A., Yvon J., 347 and Martin F. (2006). Genesis of Mayouom kaolin deposit (western Cameroon). Applied Clay 348 Science, 32, 125-140.

349 Pukanszky B., (1990). Influence of interface interaction on the ultimate tensile properties of 350 polymer composites. Composites, 21(3), 255-262.

351 Reddy M.M., Vivekanandhana S., Misra M., Bhatia S.K. and Mohanty A.K., (2013). 352 Biobased plastics and bionanocomposites: Current status and future opportunities. Progress in 353 polymer Science, 38, 1653- 1689.

354 Shogren R.L. (2009). Flocculation of kaolin by waxy maize starch phosphates. Carbohydrate 355 Polymers. 76, 639-644. 
356 Tran N.H., Wilson M.A., Milev A.S., Dennis G.R., Kannangara G.S.K. and Lam R.N., 357 (2006). Dispersion of silicate nano-plates within poly(acrylic acid) and their interfacial 358 interactions. Science and Technology of Advanced Materials, 7, 786-791.

359 Velraj G., Ramya R. and Nazni P., (2011). Fourier Transform Infrared Spectroscopic Study 360 on Glycoalkaloid Concentration in Varieties of Solanum tuberosum. Journal of Experimental 361 Sciences, 2(2), 68-71.

362 Weissenborn, P.K., Warren, L.J., Dunn, J.G., 1995. Selective flocculation of ultrafine iron 363 ore. Part 1. Mechanism of adsorption of starch onto hematite. Colloids and Surface, A99, $36411-27$.

365 Wei Y., Cheng F. and Zheng H. (2008). Synthesis and flocculating properties of cationic 366 starch derivatives. Carhoydrate polymers, 74, 673-679.

367 Wilhelm, H. M., Sierakowski, M. R., Souza, G. P., and Wypych, F. (2003). The influenced of 368 layered compounds on the properties of starch/layered compounds composites. Polymer 369 International, 52, 1035-1044.

370 Wu C.L., Zhang M.Q., Rong M.Z. and Firedrich K., (2002). Tensile performance 371 improvement of low nanoparticles filled-polypropylene composites. Composites science and 372 technology, 62, 1327-1340. 
374

375 cassava starch and kaolinite properties > origins and intensities of interactions> Interfacial 376 interactions related to starch-kaolinite composite films properties

377 


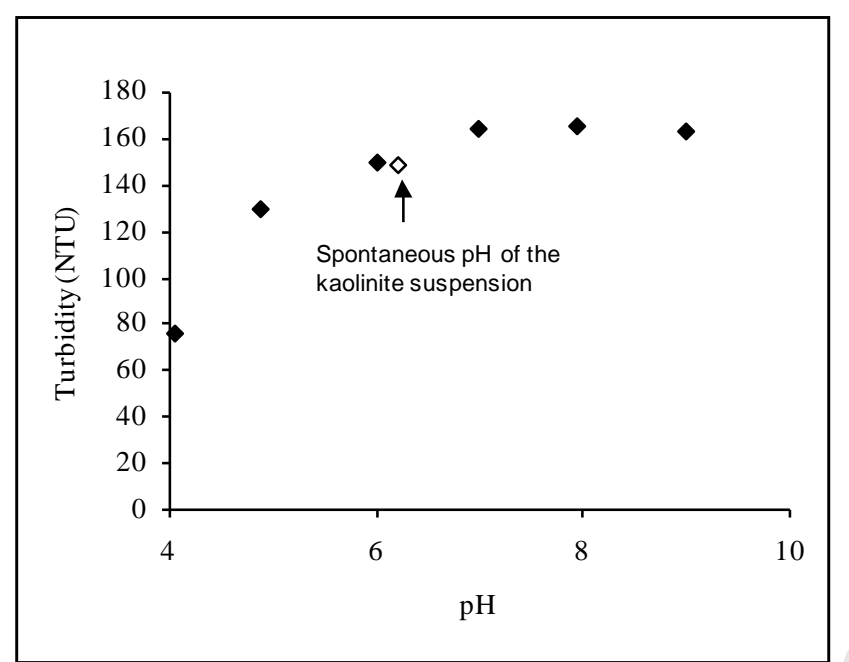

Figure 1: Analysis of the $\mathrm{pH}$ effect on the sedimentation of the kaolinite suspension 

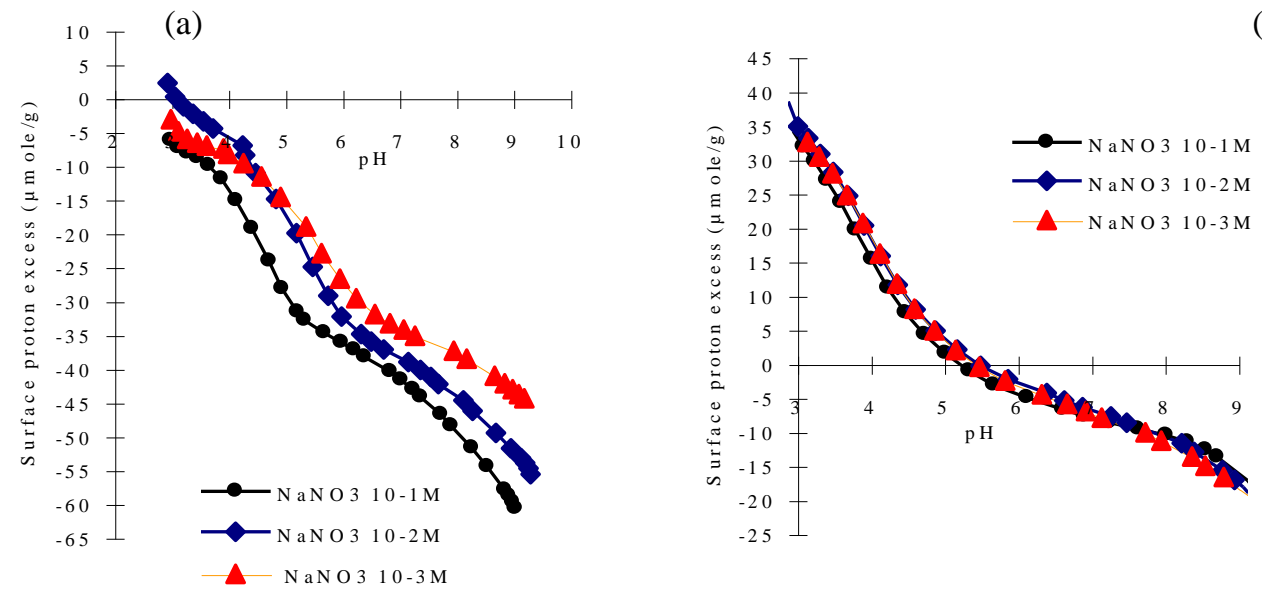

Figure 2: Surface proton excess for the kaolinite $(\sim 50 \mu \mathrm{mol} / \mathrm{g})$ (a) and the cassava starch $(\sim 43 \mu \mathrm{mol} / \mathrm{g}$ ) (b) as a function of $\mathrm{pH}$ and ionic strength 
(b)
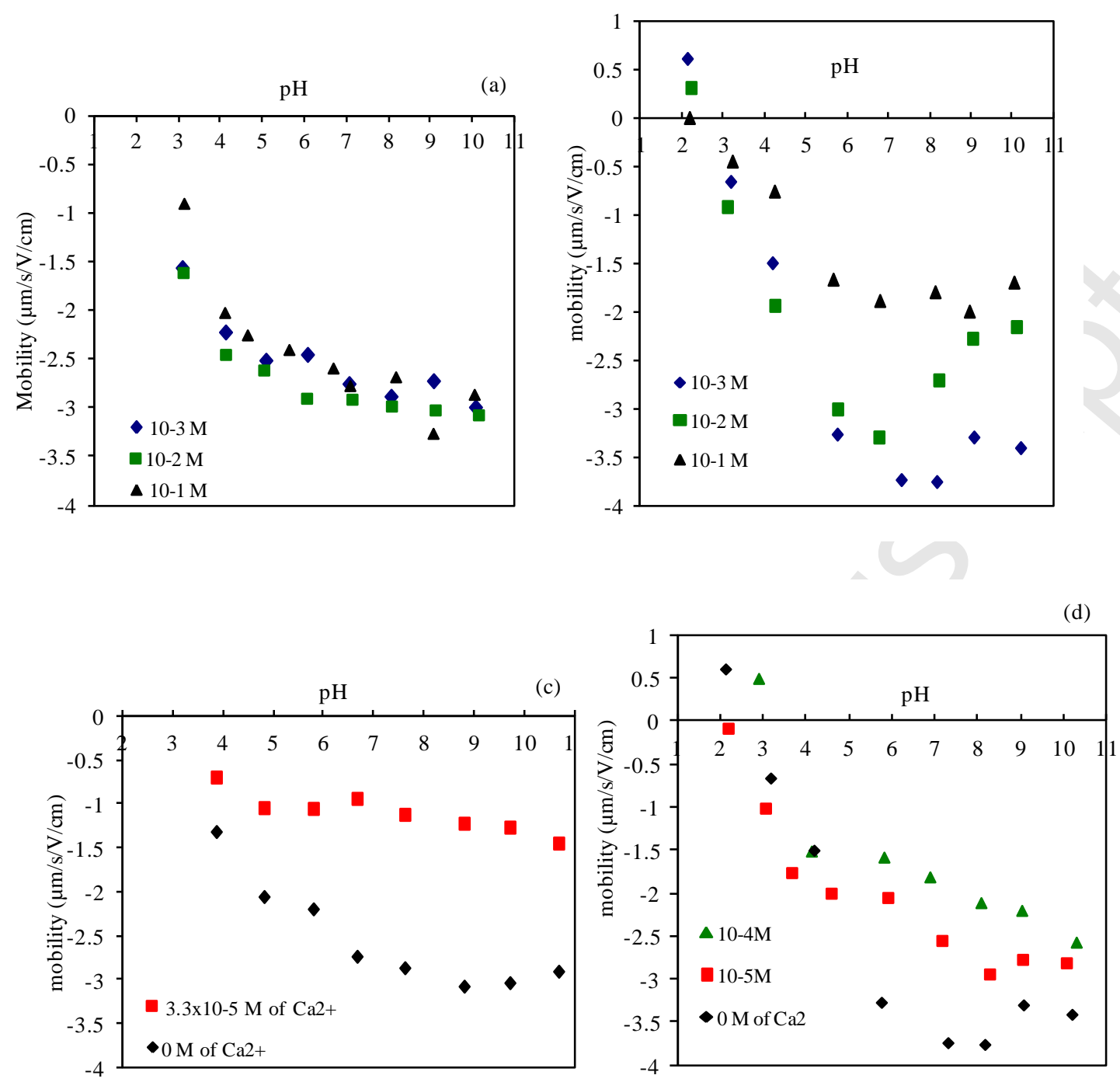

Figure 3: Electrophoretic mobility of the kaolinite (a) and the starch (b) in $\mathrm{NaNO}_{3}$ background and mobility of kaolinite (c) and starch (d) in presence of calcium cations 


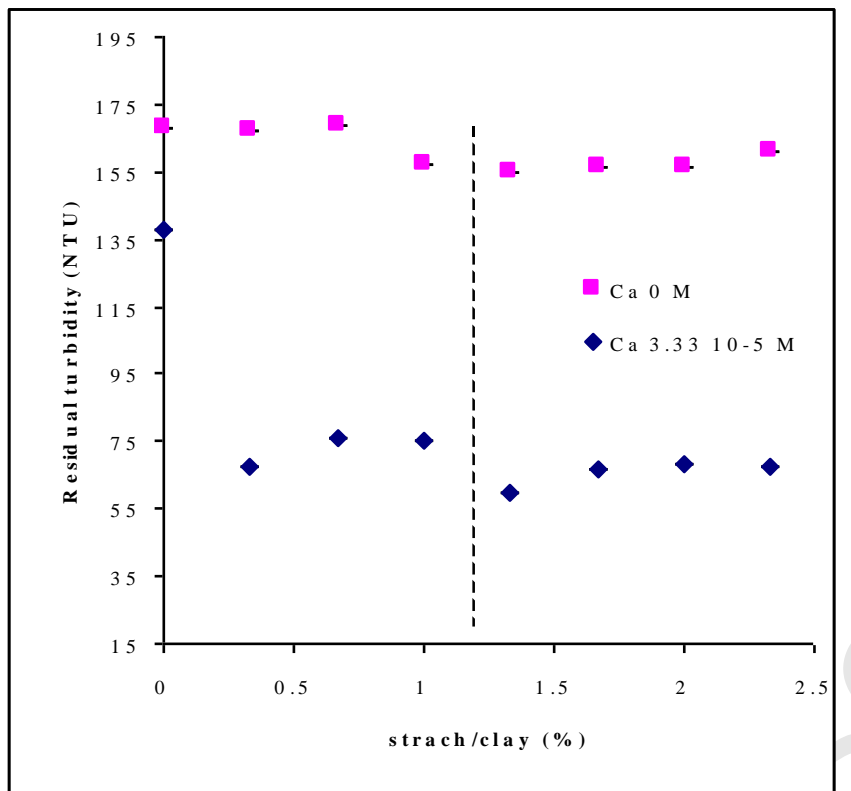

Figure 4: Turbidity measurements after 40 min sedimentation of kaolinite suspension (starting turbidity of the kaolinite suspension 235 NTU) 


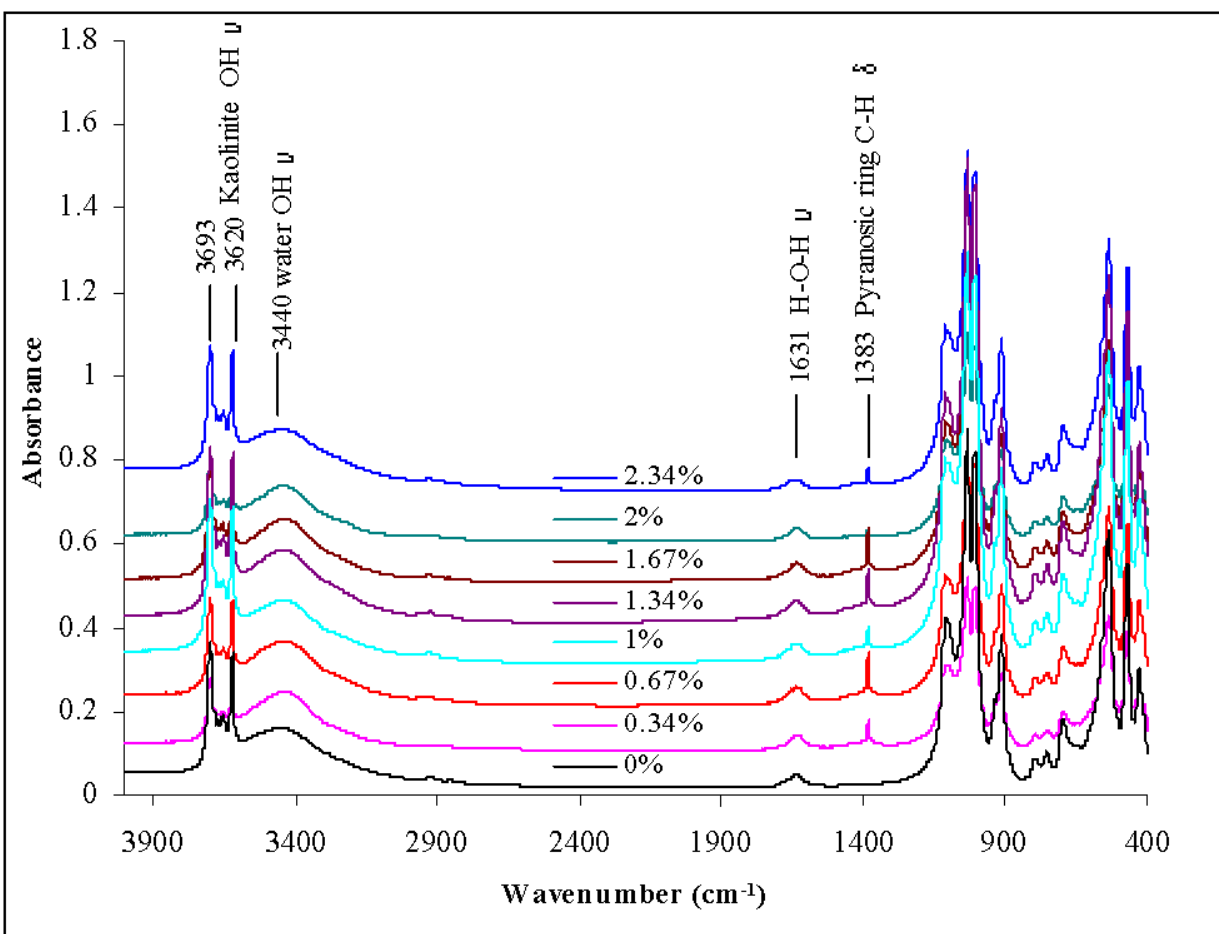

Figure 5: Infrared spectra of the kaolin-starch sediments ( $\mathrm{v}$ : stretching; $\delta$ : bending) 


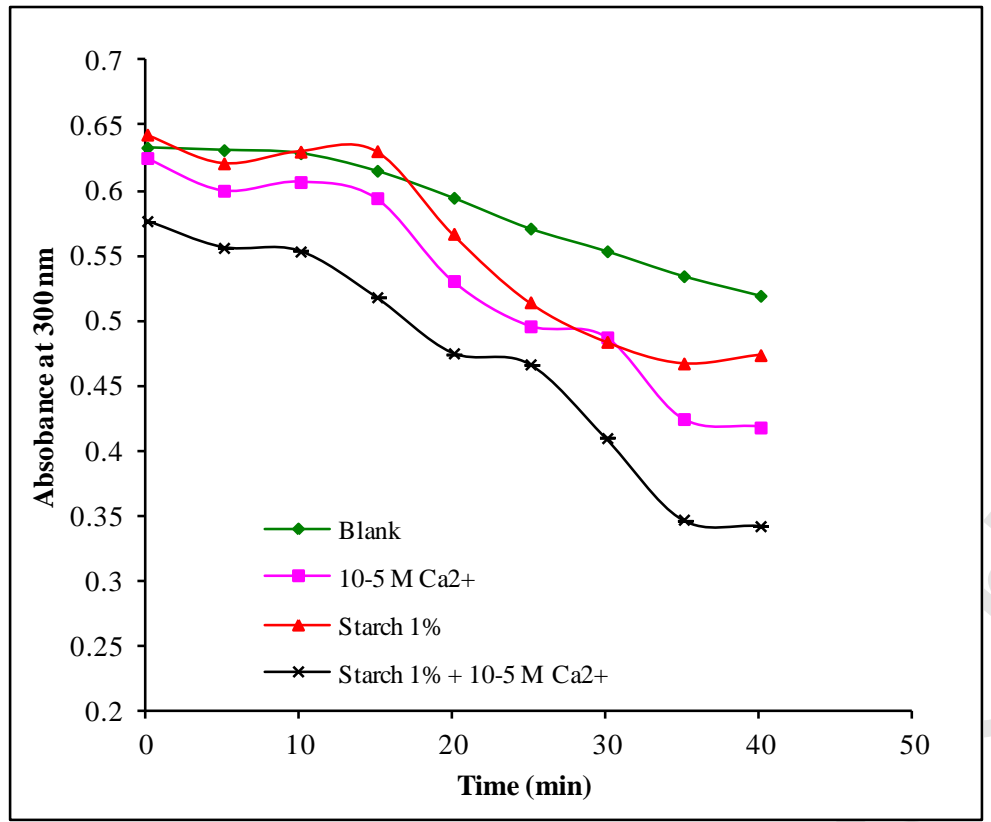

Figure 6: Uv-vis kinetic profile during kaolinite sedimentation 

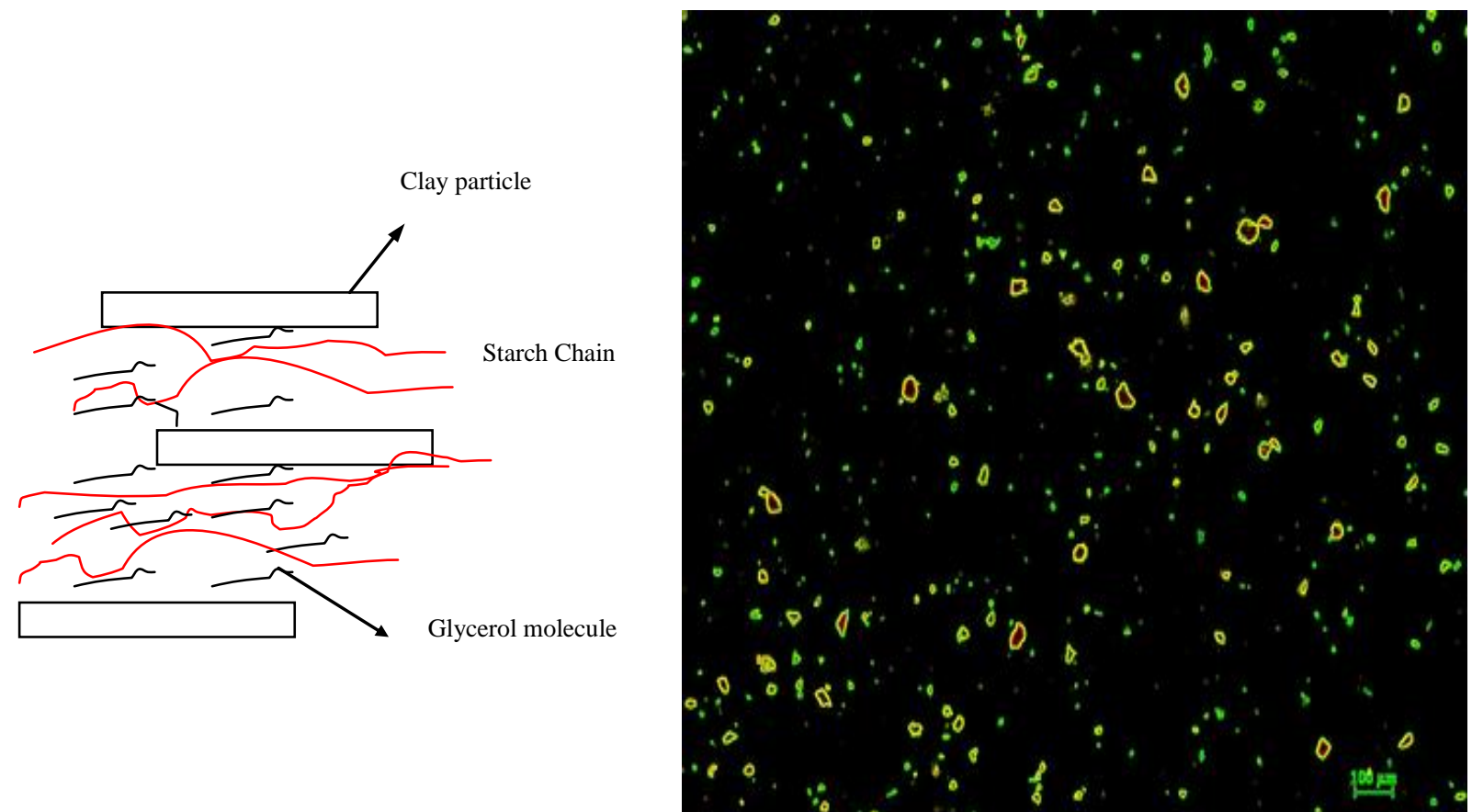

Figure 7: (a) Illustration of clay-starch interface in the composite film (b) optical micrograph of $10 \%$ loaded kaolinite cassava starch composite film analyzed for form enhancement using image $\mathrm{J}$. 


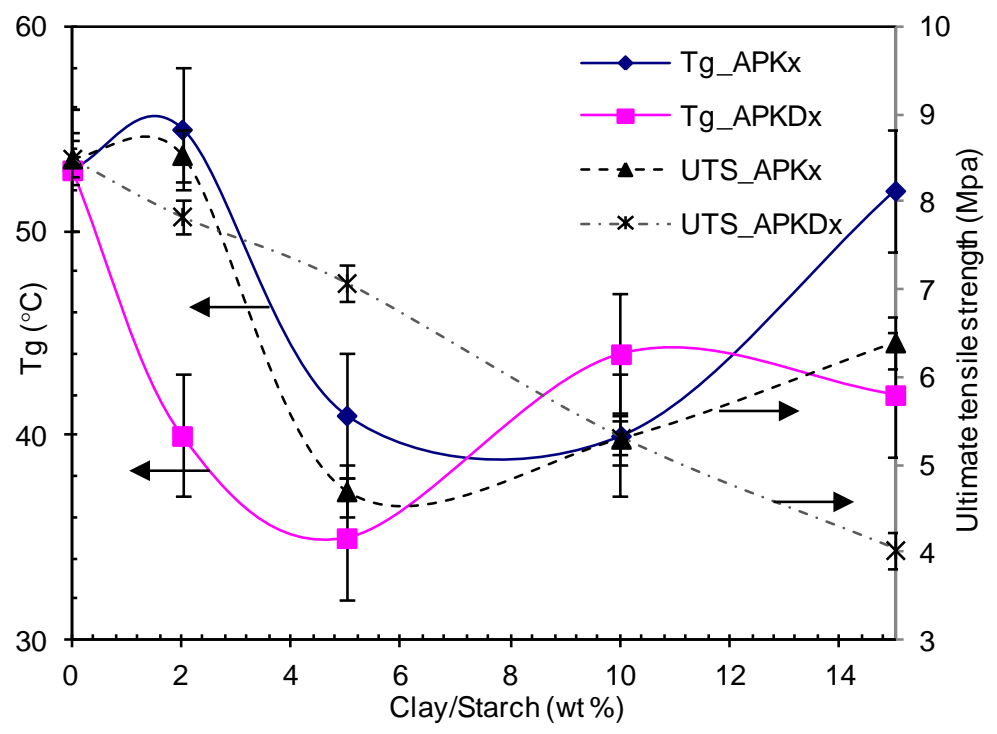

Figure 8: Variation of glass transition temperature (Tg) and ultimate tensile strength (UTS) with clay content.

APKx: films loaded with raw kaolinite and APKDx: films loaded with DMSO intercalated kaolinite 